INNOVATION AND IMPROVEMENT

\title{
Use of Simulated Patient Encounters to Teach Residents to Respond to Patients Who Discriminate Against Health Care Workers
}

\author{
Ellen $H$. Eisenberg, $M D^{1,2}$ and Kelly $A$. Kieffer, $M D, M S^{1,2}$ \\ 'Department of Medicine, Geisel School of Medicine at Dartmouth, Hanover, NH, USA; ${ }^{2}$ Section of General Internal Medicine, Dartmouth- \\ Hitchcock Medical Center, Lebanon, NH, USA.
}

BACKGROUND: Previous studies indicate that medical trainees frequently experience discrimination by patients. Little is known about effective strategies to teach trainees to respond to this discrimination.

AIM: To create a workshop for first-year residents utilizing standardized patients to improve skills in responding to patients exhibiting discrimination towards members of the health care team.

SETTING: The Patient Safety Training Center at Dartmouth-Hitchcock Medical Center in Lebanon, New Hampshire.

PARTICIPANTS: First-year residents in the Internal Medicine Residency Program.

PROGRAM DESCRIPTION: An introductory didactic session including a communication skills framework was followed by simulated encounters with four standardized patients. Learners received feedback from a trained facilitator, peers, and the standardized patients.

PROGRAM EVALUATION: One hundred percent of the 19 learners who participated agreed that the simulated exercises were realistic and improved their readiness to address patient bias. The proportion of learners who reported being somewhat or very confident in their preparedness to respond to patients exhibiting discrimination increased from $74 \%$ before the workshop to $100 \%(p=0.07)$ after the workshop.

DISCUSSION: A workshop incorporating standardized patients may improve resident confidence in responding to patients with discriminatory behaviors. The workshop could be modified to incorporate other learners and staff, or for inter-disciplinary training.

KEY WORDS: medical education-graduate; medical education-simulation; medical education-communication skills.

$\mathrm{J}$ Gen Intern Med 34(5):764-8

DOI: $10.1007 / \mathrm{s} 11606-019-04881-3$

() Society of General Internal Medicine 2019

\section{INTRODUCTION}

Multiple accounts of discriminatory behavior by patients and families towards health care providers and trainees, particularly related to racial bias, have been reported recently in the general press $^{1-4}$ and medical literature. ${ }^{5-8}$ These narratives directly or

Prior Presentation This work has not been previously presented.

Published online April 16, 2019 indirectly raise the question, "What are our obligations when we are the subject of [a patient's] inhumanity, cruelty, or intolerance?"5 They also personalize a phenomenon that has been identified in studies evaluating the frequency, nature, and sources of discrimination experienced by medical trainees.

A 2014 meta-analysis found that $21.9 \%$ of medical trainees experience harassment or discrimination by patients or patients' families. ${ }^{9} 35.2 \%$ of Canadian family medicine graduates reported experiencing intimidation, harassment, or discrimination by patients during residency, with the focus of this behavior most frequently related to gender, ethnicity, and culture. ${ }^{10}$ In a crosssectional survey of emergency medicine residents from ten institutions, $16 \%$ reported experiencing sexual harassment and $25 \%$ racial harassment by patients. ${ }^{11}$ A 2015 survey of pediatric residents at a single institution found that $15 \%$ had experienced or witnessed mistreatment, including discrimination, and $67 \%$ of the time patients' families were the source of mistreatment. ${ }^{12}$ Notably, $50 \%$ of the residents in the 2015 survey indicated that they did not know how to respond to patient and family mistreatment and $25 \%$ believed that the institution would not take action if the mistreatment was reported to hospital leadership. ${ }^{12}$

Harassment and abuse of trainees - at the hands of supervisors, staff, or patients - have been associated with the development of cynicism, depression, and other mental health consequences. ${ }^{13,14}$ While the impact of discrimination by patients on clinical care, learning outcomes, and professional development of trainees has not been well studied, there is a growing recognition that preparing medical professionals to address such situations represents an important curricular gap. ${ }^{12,15,16}$ To address this gap, we created a workshop utilizing standardized patients to teach strategies for responding to patients with discriminatory behaviors.

\section{SETTING AND PARTICIPANTS}

The Responding to Bias workshop was designed for first-year residents in internal medicine at an academic medical center. The residency program has an academic half day with protected time for first-year residents to attend weekly educational sessions. Nineteen of 25 categorical, primary care, and preliminary interns in the program were able to attend the workshop. The Patient Safety Training Center (PSTC) at the medical center 
provides space and resources for skills-based training, including a cohort of standardized patients with experience in communication training for health professionals. The workshop was led by a faculty member with assistance from four senior and chief resident facilitators who were trained prior to the workshop.

\section{PROGRAM DESCRIPTION}

A three hour workshop was designed to help learners recognize the harmful effects of discrimination towards health care providers and to communicate effectively with patients who discriminate. The content was modeled after two recent publications that outline strategies for responding to discrimination by patients and families. ${ }^{12,15}$ Participants were invited to complete a brief pre-workshop assessment of their previous experience of patient bias and of their confidence in responding to patient discrimination.

The faculty leader presented a 45 -min interactive didactic session about patient bias and discrimination, including a discussion of consequences for health providers and learners, patient safety issues, ethical and legal considerations, and suggested approaches to communicating with patients. The approaches to communication included strategies within four themes described by Whitgob and colleagues ${ }^{12}$ :

- Assessment of illness acuity - determining whether there may be a life-threatening illness which makes treating the patient or identifying another provider who can treat the first priority

- Cultivation of a therapeutic alliance - establishing rapport, exploring reasons for bias, expressing empathy, and focusing on health concerns

- Depersonalization of the event-identifying the behavior as discriminatory and recognizing that it may be motivated by fear, anxiety, loss of control, or past experiences

- Ensuring a safe learning environment-supporting colleagues and learners publically and privately, applying institutional non-discrimination policies, and seeking support from risk management when appropriate.

Following the didactic session, learners were divided into four groups, each led by a facilitator. The groups rotated through four simulation scenarios with standardized patients. Each standardized patient was provided a description of one scenario, learning objectives for the interaction, and examples of language they should use reflecting their bias. The standardized patients were instructed to escalate their discriminatory language and emotions if the learner did not apply the skills described in the learning objectives, and to de-escalate and accept care if the learner achieved the learning objectives.

Simulation scenarios included interactions with patients exhibiting gender bias, class bias, and racial bias. One patient with racial bias had an acute life-threatening illness and another had a non-urgent concern (see Table 1). In order to maintain consistency with residents of different racial backgrounds and to teach residents to support a learner who is the target of discrimination, the scenarios involving patients expressing racial bias involved a medical student to whom discrimination was directed but who was not in the room during the exercise.

Each learner had the opportunity to interact directly with one standardized patient while the remainder of the group and the facilitator observed behind a one-way mirror. Learners received a brief description of the clinical situation without information about the patient's background or bias. The facilitator used a simulation observation worksheet (see Online Appendix) to make notes about learner behaviors, communication strategies used during the simulation, and missed opportunities to apply communication strategies. The facilitator led a structured debriefing session after each exercise. Each learner received feedback from the facilitator, other members of the group, and the standardized patients.

After the groups completed the simulation scenarios, the learners and facilitators reconvened to discuss the session, share key learning points, and give feedback regarding the structure and content of the workshop. Participants were invited to complete a post-workshop evaluation and assessment of their confidence in addressing discrimination by patients.

\section{PROGRAM EVALUATION}

All 19 participants completed the anonymous pre- and postworkshop assessments. In the pre-workshop assessment, we asked learners about their experiences with patients or patient family members exhibiting bias based on inherent traits including race, ethnicity, nationality, religion, gender, sexual orientation, disability, physical appearance, or class. Ten participants $(53 \%)$ reported that they had personally experienced bias from a patient or family member in the form of "inappropriate, disrespectful, or derogatory remarks." Fifteen (79\%) reported witnessing bias directed towards another member of the care team, $12(63 \%)$ indicated that they had witnessed such bias on more than one occasion, and 4 (21\%) reported that a patient or family member had asked that they be removed from a care team because of one or more of their inherent traits. Despite the high frequency of exposure to patients exhibiting bias, only $3(16 \%)$ reported any previous education or training in responding to patients or family members demonstrating discriminatory behaviors or bias.

The post-workshop assessment included questions about the effectiveness of the workshop using a 4-point Likert scale with answer options "strongly agree," "agree," "disagree," and "strongly disagree." Nineteen (100\%) participants agreed or strongly agreed that "the simulated exercises represented realistic scenarios involving patient bias," "the simulated exercises improved my readiness to address patient bias in the future," "the feedback I received in the group debrief helped me identify my personal areas of strength and opportunities for improvement," and "I would recommend this exercise to other 
Table 1 Description of Simulation Scenarios and Associated Learning Objectives

\begin{tabular}{|c|c|c|c|c|}
\hline $\begin{array}{l}\text { Type of } \\
\text { bias }\end{array}$ & Clinical scenario & Bias scenario & $\begin{array}{l}\text { Examples of patient } \\
\text { language }\end{array}$ & $\begin{array}{l}\text { Primary learning } \\
\text { objectives }\end{array}$ \\
\hline Gender & $\begin{array}{l}\text { Middle-aged man with } \\
\text { acute back pain, } \\
\text { presenting to a female } \\
\text { provider in clinic }\end{array}$ & $\begin{array}{l}\text { The patient is condescending towards } \\
\text { the physician and questions the } \\
\text { competence of women as doctors. }\end{array}$ & $\begin{array}{l}\text { - Are you the nurse? } \\
\text { - Women should not } \\
\text { be doctors. } \\
\text { - Are you married? } \\
\text { Do you have } \\
\text { children? You should } \\
\text { be home raising a } \\
\text { family. } \\
\text { - I want to see a male } \\
\text { physician. }\end{array}$ & $\begin{array}{l}\text { The learner acknowledges the bias, } \\
\text { attempts to understand the patient's } \\
\text { concerns, assures the patient of her } \\
\text { qualifications, and attempts to care for the } \\
\text { patient. }\end{array}$ \\
\hline Class & $\begin{array}{l}\text { New onset knee pain, } \\
\text { presenting to clinic }\end{array}$ & $\begin{array}{l}\text { The patient is a wealthy donor who } \\
\text { becomes angry when the resident } \\
\text { recommends conservative care. } \\
\text { The patient demands an MRI and } \\
\text { orthopedics consultation and uses } \\
\text { power related to their socioeconomic } \\
\text { status to coerce the resident to agree to } \\
\text { the requested referrals. }\end{array}$ & $\begin{array}{l}\text { - I donate a lot of } \\
\text { money to the hospital, } \\
\text { I deserve better care. } \\
\text { - You do not know } \\
\text { what you are doing, } \\
\text { you are just an intern. } \\
\text { - Do you know who } \\
\text { I am? }\end{array}$ & $\begin{array}{l}\text { The learner attempts to develop a } \\
\text { therapeutic alliance, displays compassion, } \\
\text { and expresses empathy regarding the } \\
\text { patient's pain and concerns. }\end{array}$ \\
\hline Racial & $\begin{array}{l}\text { Acute chest pain with } \\
\text { dyspnea at rest, } \\
\text { presenting to the } \\
\text { emergency department }\end{array}$ & $\begin{array}{l}\text { The patient expresses anger regarding a } \\
\text { medical student of color who is part of } \\
\text { the team and refuses care unless assured } \\
\text { that the student will not be involved in } \\
\text { his or her care. }\end{array}$ & $\begin{array}{l}\text { - I do not want that } \\
\text { student to touch me } \\
\text { again. } \\
\text { - I do not want a } \\
\text { "quota" doctor taking } \\
\text { care of me. } \\
\text { - I want a different } \\
\text { team with only white } \\
\text { people. }\end{array}$ & $\begin{array}{l}\text { The learner first focuses on assessing and } \\
\text { stabilizing the patient's acute medical } \\
\text { condition, expresses confidence in all } \\
\text { members of the team, and negotiates a } \\
\text { change in team if needed to provide } \\
\text { emergent care for the patient. }\end{array}$ \\
\hline Racial & $\begin{array}{l}\text { Chronic migraine } \\
\text { headaches, presenting } \\
\text { to clinic }\end{array}$ & $\begin{array}{l}\text { The patient expresses anger regarding a } \\
\text { medical student of color who is part of } \\
\text { the team and refuses care unless assured } \\
\text { that the student will not be involved in } \\
\text { his or her care. }\end{array}$ & $\begin{array}{l}\text { - I am glad you are } \\
\text { not black too. } \\
\text { - That student should } \\
\text { go back where they } \\
\text { came from. } \\
\text { - Those people should } \\
\text { not be physicians. } \\
\text { They are not smart } \\
\text { enough. }\end{array}$ & $\begin{array}{l}\text { The learner attempts to develop a } \\
\text { therapeutic alliance, expresses confidence } \\
\text { in all members of the team, and refers to } \\
\text { the institutional policy of } \\
\text { nondiscrimination. }\end{array}$ \\
\hline
\end{tabular}

residents." Eighteen (95\%) agreed or strongly agreed that "the didactic material effectively conveyed the communication skills we were expected to practice in the simulated patient exercises."

We assessed learner confidence in responding to discriminatory patients in the pre-workshop and post-workshop assessments using a 4-point Likert scale with answer options "not at all confident," "somewhat unconfident," "somewhat confident," and "very confident." Prior to the workshop, 14 (74\%) learners reported being somewhat or very confident in their ability to respond effectively to a patient directing overt discriminatory comments towards them personally, and 14 (74\%) reported being somewhat or very confident regarding their ability to respond to a patient making such comments towards another member of the team. After the workshop, $100 \%$ were somewhat or very confident about addressing discriminatory comments in both situations ( $p=0.07$ by McNemar's chi-square test for change in confidence regarding both questions; see Fig. 1 for descriptive statistics demonstrating the distribution of reported confidence scores).

Two participants gave suggestions for improvement. One suggested a scenario involving a patient expressing bias based on religion. Another suggested making the cases more confrontational and including a racial bias case in which the learner was the direct target of the patient's discrimination rather than a third party.

\section{DISCUSSION}

Bias and discrimination towards clinicians by patients and families are well documented. This is a growing concern with increasing diversity in the general population and among the healthcare workforce, and in the context of a vigorous national dialog about racism, sexism, and bias based on religion and sexual orientation. Consistent with published literature, many of our residents had experienced discriminatory behavior by patients but few indicated that they had received training on responding to that behavior.

Navigating the issues involved in dealing with patient bias and discrimination is challenging. Doctors have a duty to treat, and patients have the right to refuse care if they are mentally competent and understand the consequences of their refusal. Employment law and institutional policies regarding discrimination in the work place protect health care workers from being removed from their roles in response to discriminatory comments and behaviors by patients. ${ }^{17}$ The Responding to 

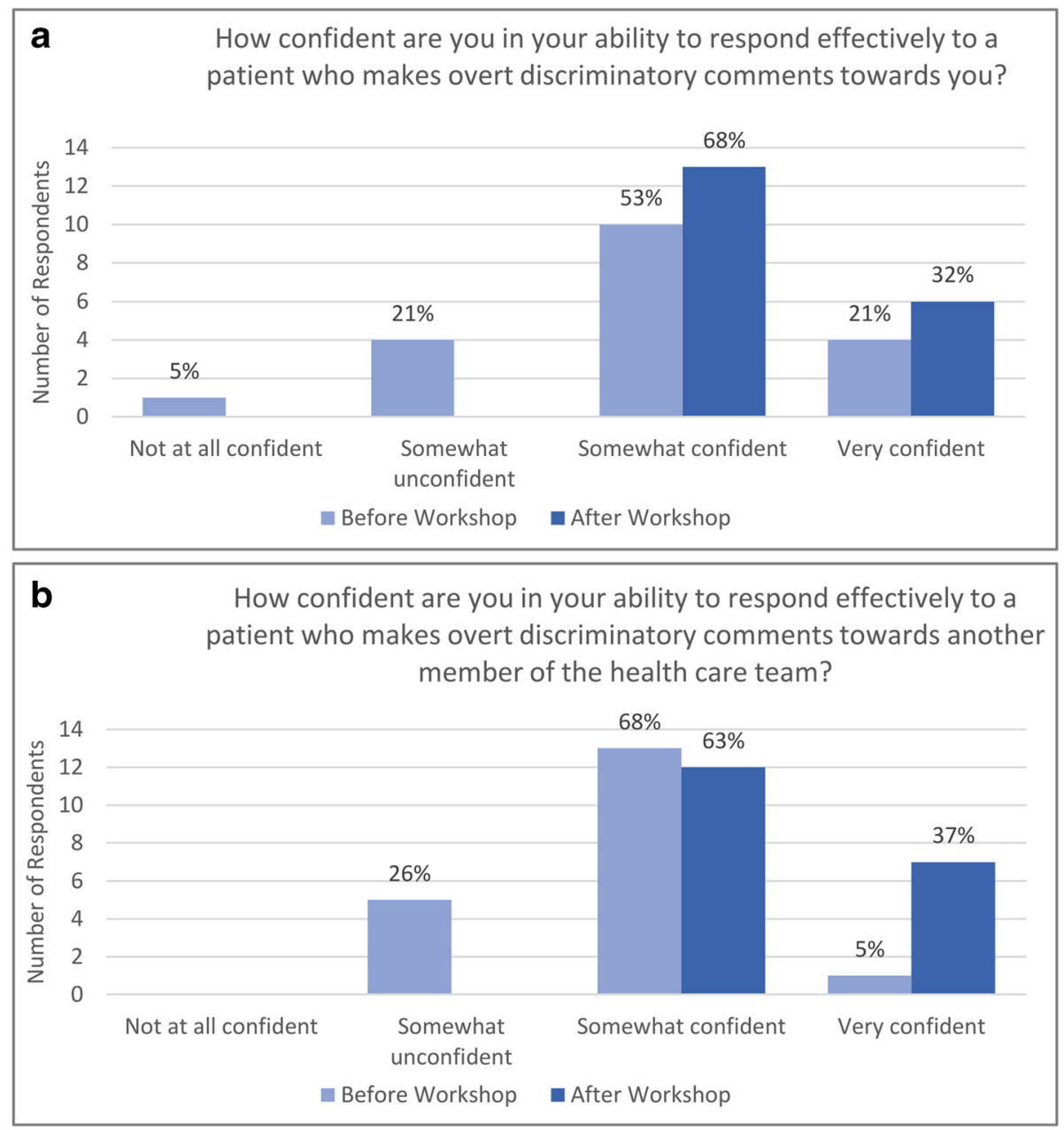

Figure 1 Participants' reported confidence in responding to discriminatory patients. Self-reported confidence in responding to patients expressing discrimination towards self (a) and another member of the team (b) before and after the workshop; $n=19$ for both questions.

Bias workshop provides a roadmap for learners, utilizing an interactive approach to address complex and potentially stressful situations. Simulation delivers a "real-time" experience for developing communication skills in a safe, learner-centered environment with feedback from facilitators, peers, and trained standardized patients. ${ }^{18}$ The curriculum is designed to teach clinicians and educators skills to directly and effectively address discrimination grounded in racial, gender, or class bias; support colleagues and learners; and assure that patients receive appropriate care.

The Responding to Bias workshop was favorably received by residents in our program. Residents' self-reported confidence in responding to discrimination increased after the workshop, but this change did not reach statistical significance. This assessment involved a small number of residents from a single institution, limiting statistical power and generalizability. Our outcome assessments - learner satisfaction and self-assessed confidence - also have limitations; confidence in a simulation setting does not ensure competence in a clinical environment. Nonetheless, the initial positive results are promising. We plan to continue delivering, evaluating, and refining the workshop with future cohorts of first-year residents, and to provide follow-up training as residents progress through the program. Additionally, we plan to video record simulation exercises during a future workshop and select interactions between learners and simulated patients to use as examples during the pre-simulation didactics, in other workshops, and to train facilitators. In addition to assessing confidence one year after the workshop, we plan to survey participants regarding clinical situations in which they applied the communication skills, and the extent to which the workshop affected their approach to patients and learners.

We also see opportunities to modify the workshop for learners at other levels and professionals in multiple disciplines, and for inter-disciplinary training. Nurses, advanced practice clinicians, and other health professionals who engage in direct patient care are at risk for bias and discrimination by patients and could benefit from this program. In addition, we intend to adapt the workshop for faculty development. We believe that introducing a broad range of learners and staff to the Responding to Bias workshop will multiply its value, reinforce a culture of safety and well-being, and foster muchneeded conversation about the impact of discrimination in health care. 
Contributors: The authors are the sole contributors to the writing and preparation of this manuscript.

Corresponding Author: Ellen H. Eisenberg, MD; Section of General Internal Medicine, Dartmouth-Hitchcock Medical Center, One Medical Center Drive, Lebanon, NH 03756, USA (e-mail: Ellen.H. Eisenberg@hitchcock.org).

Funders The work described was supported by an internal grant from the Dartmouth-Hitchcock Medical Center Department of Medicine Advisory Council for Education.

\section{Compliance with Ethical Standards:}

Conflict of Interest: Dr. Kelly Kieffer received an honorarium in January 2017 from Medscape for an educational video supported by Abbvie and Pfizer. Dr. Ellen Eisenberg reports no potential conflicts of interest.

Prior Presentation: This work has not been previously presented.

Publisher's Note Springer Nature remains neutral with regard to jurisdictional claims in published maps and institutional affiliations.

\section{REFERENCES}

1. Chen PW. When the patient is racist [Internet]. New York: The New York Times. 2013 [cited 2018 Dec 4]. Available from: https://well.blogs. nytimes.com/2013/07/25/when-the-patient-is-racist/

2. Novick DR. Racist patients often leave doctors at a loss [Internet] Washington DC: The Washington Post. 2017 [cited 2018 Dec 4]. Available from: https://www.washingtonpost.com/opinions/racist-patients-oftenleave-doctors-at-a-loss /2017/10/19/9e9a2c46-9d55-11e7-9c8dcf053ff30921_story.html?utm_term=.131b470f054b

3. Trogen B, Caplan A. When a patient is a bigot, what can a doctor do? [Internet]. Chicago: Chicago Tribune. 2017 [cited 2018 Dec 4]. Available from: http://www.chicagotribune.com/news/opinion/commentary/ctdoctors-bigot-patients-discrimination-perspec-20170629-story.html

4. Reddy S. How doctors deal with racist patients [Internet]. New York: Wall Street J. 2018 [cited 2018 Dec 4]. Available from: https://www.wsj.com/ articles/how-doctors-deal-with-racist-patients- 1516633710

5. Jain SH. The racist patient. Ann Intern Med. 2013; 158:632.

6. Reynolds KL, Coweden JD, Brosco JP, Lantos JD. When a family requests a white doctor. Pediatrics. 2015; 136; 381-386.

7. Lane-Fall M. Accommodating Bigotry. JAMA. 2014; 311:39-140.

8. Gupta R. Slaves. Ann Intern Med. 2016;165:671-672.

9. Fnais $\mathbf{N}$, Soobih $\mathbf{C}$, Chen $\mathbf{M H}$, et al. Harassment and discrimination in medical training: a systematic review and meta-analysis. Acad Med. 2014; 89:817-827.

10. Crutcher RA, Szafran O, Woloschuk W, Chatur F, Hansen C. Family medicine graduates' perceptions of intimidation, harassment, and discrimination during residency training. BMC Med Educ. 2011 [cited 2018 Dec 4]; Available from: https://bmcmededuc.biomedcentral.com/track/ pdf/10.1186/1472-6920-11-88

11. Li SF, Grant $\mathbf{K}$, Bhoj T, et al. Resident experience of abuse and harassment in emergency medicine: ten years later. J Emer Med. 2008:38: 248-252.

12. Whitgob E, Blankenburg $\mathbf{R}, \mathbf{B o g e t z} \mathbf{A}$. The discriminatory patient and family: strategies to address discrimination towards trainees. Acad Med. 2016;91: s64-s68.

13. Silver HK, Glicken AD. Medical student abuse. JAMA. 1990; 263: 527-532.
14. Richman JA, Flaherty, JA, Rospenda KM, Christensen ML. Mental health consequences and correlates of reported medical student abuse. JAMA. 1992; 267:692-694.

15. Paul-Emile K, Smith A, Lo B, Fernandez A. Dealing with racist patients. NEJM. 2016: 374,8: 708-711.

16. Nelson WA, Huang A. Discrimination and patient-centered care. Healthcare Exec 2017; 32:54-56.

17. Warshaw $\mathbf{R}$ When the target of bias is the doctor [Internet]. Washington, DC: AAMCNews. 2017 [cited 2018 Dec 4]. Available from: https://news. aamc.org/patient-care/article/target-bias-doctor/

18. Cleland JA, Abe K, Rethans $\mathbf{J}$. The use of simulated patients in medical education: AMEE guide No 42. Med Teach 2009; 31:477-486.

\section{APPENDIX. STRATEGIES FOR APPROACHING A BIASED PATIENT-FACILITATOR WORKSHEET}

Use this form to record your observations of the learner's interactions with the simulated patient. Note examples of successful use of these strategies and any missed opportunities. These observations may help prompt discussion during the debrief session.

\section{Assess Illness Acuity}

Factor illness severity and acuity into the response to the situation

Consider whether finding another provider is a safe and preferable option

\section{Cultivate a Therapeutic Alliance}

Build rapport

Explore biases without intention of changing beliefs

Focus on concerns about getting health problems addressed

Describe team structure and how everybody on the team participates in patient care

\section{Depersonalize the Event}

Explore the possibility that bias is motivated by patient's fear and anxiety

Explore how bias might be motivated by past experience of the patient

Name the behavior as discriminatory

\section{Ensure a Safe Learning Environment (may be addressed during debrief)}

If a trainee is involved, provide support and assurance of trainee competence

Explore trainee's reaction, encourage trainee to come up with next steps

Involve risk management when appropriate 